\title{
Effect of Iron on Taste Perception and Emotional Response of Sweetened Beverage under Different Water Conditions
}

\author{
Aili Wang ${ }^{\mathrm{a}}$, Susan E. Duncan ${ }^{\mathrm{a}^{*}}$, Andrea M. Dietrich ${ }^{\mathrm{b}}$ \\ a Department of Food Science and Technology, 1230 Washington St. SW, Virginia Polytechnic \\ Institute and State University (Virginia Tech), Blacksburg, VA 24061, USA; waili9@ vt.edu; \\ duncans@vt.edu \\ ${ }^{b}$ Department of Civil and Environmental Engineering, 1145 Perry Street, Virginia Tech, \\ Blacksburg, VA 24061, USA; andread@vt.edu \\ *Corresponding author: $\quad$ Tel: +1 540-231-6806; Fax: +1 540-231-9293 \\ Email: duncans@vt.edu \\ Address: $\quad$ Human and Agricultural Biosciences Building 1 \\ (HABB1) \\ 1230 Washington St. SW \\ Virginia Tech \\ Blacksburg, VA 24061 USA
}

(C) 2016. This manuscript version is made available under the Elsevier user license 
Abstract: Although sweeteners are widely used additives in beverages, taste interaction between sweeteners and minerals in water is rarely reported. The objective was to investigate the influence of different concentrations of iron and water hardness on taste perception of sweetened beverages and characterize the corresponding emotional profiles. Taste interaction was developed by dissolving five natural and artificial sweeteners [sucrose, honey, sucralose, saccharin, and acesulfame potassium (ace-K)] into four synthetic waters [soft water (0 mg Fe/L), moderate hard water $(0.3 \mathrm{mg} \mathrm{Fe} / \mathrm{L})$, hard water $(1 \mathrm{mg} \mathrm{Fe} / \mathrm{L})$ and very hard water $(3 \mathrm{mg} \mathrm{Fe} / \mathrm{L})]$, respectively. Sweet and metallic taste intensity of different combinations were compared by pairwise ranking tests. Acceptability and emotional response on sucrose sweetened beverage with and without the addition of iron was evaluated by 9-point hedonic score test and check-allthat-apply emotional term ballot. Iron $\left(\mathrm{Fe}^{2+}\right)$ created metallic flavor in drinking water and produced bored and disgusted feelings for consumers. Other minerals such as $\mathrm{Ca}^{2+}, \mathrm{Mg}^{2+}$ and $\mathrm{Na}^{+}$at subthresholds impacted taste perception of water. Sweetness of sweeteners was varied with different concentrations of minerals in water and with different types of sweeteners. High concentration of iron and water hardness significantly increased $(p<0.05)$ the sweetness of sucrose, honey and ace-K. Sweet-metallic taste interaction between sucrose and ferrous ions significantly $(\mathrm{p}<0.05)$ increased the acceptance of very hard water $(3 \mathrm{mg} \mathrm{Fe} / \mathrm{L})$, and created a unique emotional profile- "mild". Distribution of emotional profiles could be different between samples with the same hedonic scores and provide more in-depth information than acceptance test.

Key Words: sweet, metal, water, beverage, emotion, taste interaction 


\section{Introduction}

Water is critical to beverage production and its quality directly influences the taste and acceptability of the corresponding beverage products. Water quality is classified by the composition and concentration of the containing minerals, which can add salty, bitter, sweet or metallic flavor to water (Burlingame, Dietrich, \& Whelton, 2007; Dietrich \& Burlingame, 2015). When minerals reach certain concentrations, they may deeply impact taste perception of final products by interacting with each other or reacting with other food constituents. In the food industry, water used for beverage production has to meet drinking water standards established by US Environmental Protection Agency. However, minerals without toxic effects but influencing taste perception of water are regulated by Secondary Drinking Water Regulations (USEPA, 2016), which are guidelines for public water systems followed on a voluntary basis for most states in United States. Corrosion of metal piping is an additional source of excess metal ions in tap water (Lauer, 2004; Dietrich, Glindenmann, Pizarro, Gidi, Olivares, Araya, Camper, Duncan, Dwyer, Whelton, Younos, Subramanian, Burlingame, Khiari, \& Edwards, 2004; Duranceau, Wilder, \& Douglas, 2012).

Many companies provide additional water filtration and treatment steps to standardize their water supply. However, such processes are expensive and may not be feasible for small companies. Consumers may also have filters at the tap to reduce minerals in their drinking water. However, their home made beverages (such as coffee, tea, beer, wine) may be affected by residual minerals. Therefore, high concentration of mineral ions found in the supplied water may greatly impact taste perception if used in beverage production.

Humans are sensitive to many minerals; some thresholds are below the maximum amount set by Secondary Drinking Water Regulations (USEPA, 2016). Copper can be detected at very 
low concentration ranging from 0.5-13 mg/L (Jesse, Cohen, Kamphake, \& Richard, 1960;

Cuppett, Duncan, \& Dietrich, 2006); the Secondary Drinking Water Standards for copper is 1.0 $\mathrm{mg} / \mathrm{L}$ (USEPA, 2016). Iron is one of the most noticeable minerals since it can impart metallic flavor in drinking water as low as $0.17 \mathrm{mg} / \mathrm{L}$ (Mirlohi, Dietrich, \& Duncan, 2011), which is below the secondary drinking water standard for iron set at $0.3 \mathrm{mg} / \mathrm{L}$. Furthermore, iron is found most frequently in water supplies since it is the fourth most common element found in the Earth's crust and widely spread in the natural environment. Effects of iron and other minerals on metallic flavor of drinking water have been reported. Iron (II) sulfate was represented metallic sensation in deionized water and the metallic sensitivity could be weakened with the existence of other minerals (Hoehl, Schoenberger, \& Busch-Stockfisch, 2010). However, a commercial food product is a comprehensive flavor system with many interactions; a single taste never exists. Thus, how minerals influence taste perception of beverages through interaction with other taste stimuli still needs further study.

Taste interactions are important to the development and modification of food products and have been widely studied for decades. Taste interaction between same taste stimuli including sweet (Ayya, \& Lawless, 1992; Schiffman, 1995), umami (Yamaguchi, 1967), salt (Breslin \& Beauchamp, 1995), sour (Bartoschuk \& Cleveland, 1977) and bitter (Keast \& Breslin, 2002b), and between multiple taste stimuli such as umami/salt (Woskow, 1969; Keast \& Breslin, 2002a), salt/sour (Breslin, 1996), bitter/salt (Breslin \& Beauchamp, 1995; Breslin \& Beauchamp, 1997), bitter/sour (Pangborn, 1960; Keast \& Breslin, 2002a), sweet/salt (Beebe-Center, Rogers, Atkinson, \& O'Connell, 1959; Breslin, 1996), sweet/sour (Curtis, Stevens, \& Lawless, 1984), and bitter/sweet (Schiffman, Gatlin, Sattely-Miller, Graham, Heiman, Stagner, \& Erickson, 1994; Calvino, Garcia-Medina, \& Cometto-Muniz, 1990) were reported in previous studies. 
However, binary taste interaction between sweet and metallic flavor have not been previously reported.

Different from other taste perception, metallic sensation is a combination of metallic taste and retronasally perceived odor (Mirlohi et al., 2011). Metallic taste is characterized as bitter and salty taste as well as astringent mouthfeel (Ömur-Özbek, \& Dietrich, 2011) and often carries a lingering aftertaste (Hong, Duncan, \& Dietrich, 2009). Metallic flavor is widely observed as an undesirable sensory side effect. It has been associated with polyphenols in cloudy raw fruit juices, some meat products, and metal ions found in drinking water (Sarin, Snoeyink, Lytle, \& Kriven, 2004), and attributed to metal from containers during production, storage and transportation. Some alternative sweeteners, such as acesulfame potassium (ace-K) and saccharin, may also contribute low levels of bitter, astringent and metallic characteristics at higher concentrations (Horne, Lawless, Speirs, \& Sposato, 2002). It is recognized that metallic flavor is a negative attribute and can reduce product acceptability.

Consumer acceptability of a food product is the traditional approach for estimating potential purchase/consumption behavior; however, product success does not always follow this measure. Correlation between consumer emotional response and sensory experience during food consumption has been explored in recent years to provide additional information on prediction of product success (Leitch, Duncan, O’Keefe, Rudd, \& Gallagher, 2015; Walsh, Duncan, Potts, \& Gallagher, 2015). Emotional response can help describe the impact of sensory quality on consumer hedonic response (King \& Meiselman, 2010). However, no study has related emotional response to perception of taste interactions to our knowledge.

Our study objective was to document the influence of different concentrations of iron and water hardness on taste perception of sweetened water beverages. Taste interaction was 
investigated by detecting sweet and metallic intensity generated from combinations of four synthetic waters and five commercial sweeteners. In addition, emotional response in combination with acceptance tests was applied to study sweet-metallic interaction between sucrose and ferrous sulfate.

\section{Materials and Methods}

\subsection{Materials}

Food-grade chemicals including iron (II) sulphate heptahydrate $\left(\mathrm{FeSO}_{4} \cdot 7 \mathrm{H}_{2} \mathrm{O}\right)$, sodium bicarbonate $\left(\mathrm{NaHCO}_{3}\right)$, calcium sulfate dihydrate $\left(\mathrm{CaSO}_{4} \cdot 2 \mathrm{H}_{2} \mathrm{O}\right)$, magnesium sulfate heptahydrate $\left(\mathrm{MgSO}_{4} .7 \mathrm{H}_{2} \mathrm{O}\right)$, and potassium chloride $(\mathrm{KCl})$ were purchased from Spectrum Chemical (New Brunswick, NJ). Acesulfame potassium (ace-K) was received from Wego Chemical \& Mineral Co. (Great Neck, NY) and sucralose was received from Sucral (Tate \& Lyle; London). Saccharin, honey (clover) and sucrose (Kroger; Cincinnati, OH) were purchased at the local supermarket. Distilled water, drinking water and unsalted soda crackers were purchased from Kroger (Kroger brand, Cincinnati, $\mathrm{OH}$ ).

\subsection{Preparation of iron-containing sweetened beverage}

Preparation of synthetic water

The preparation of synthetic soft water followed the formulation of minerals for hard and soft natural waters in 100 large cities in the United States as described by Burlingame et al. (2007) and Smith, Davison, \& Hamilton-Taylor (2002) with slight modification. To prepare synthetic water with appropriate hardness (DES, 2008), mineral concentration in moderate hard, hard and very hard water was determined through multiplying mineral ions concentration in soft water by $2.5,5$, and 7.5 , respectively (Table 1 ). Synthetic very hard water (4L) was prepared daily with food grade chemicals following the compositions in Table 1. Distilled water (3.8 L) (The Kroger 
Co., Cincinnati, $\mathrm{OH}, 45202)$ was purchased in a clean glass bottle, to which was added $461.9 \mathrm{mg}$ $\mathrm{MgSO}_{4} .7 \mathrm{H}_{2} \mathrm{O}, 635.5 \mathrm{mg} \mathrm{NaHCO}_{3}$ and $114.7 \mathrm{mg} \mathrm{KCl}$. The solution was aerated with magnetic stirrer overnight. The next day, $1367.4 \mathrm{mg}$ of $\mathrm{CaSO}_{4} \cdot 2 \mathrm{H}_{2} \mathrm{O}$ was added to $200 \mathrm{~mL}$ distilled water in a separate glass beaker with stirring. After the calcium sulfate was totally dissolved, the solution was added to the $3.8 \mathrm{~L}$ solution and mixed well. The combined solution was aerated vigorously with magnetic stirrer for an additional $24 \mathrm{~h}$ to dissolve the added chemicals and stabilize the medium. Then the prepared very hard water was diluted by distilled water at the ratio 1:6.5 for soft water, 1:4 for moderate hard water and 1:1.5 for hard water (Table 1). Right before sensory testing, $1.5 \mathrm{mg}$ of $\mathrm{FeSO}_{4} \cdot 7 \mathrm{H}_{2} \mathrm{O}$ was dissolved in $1 \mathrm{~L}$ synthetic moderately hard water, $5.0 \mathrm{mg}$ was dissolved in 1L synthetic hard water, and $14.9 \mathrm{mg}$ was dissolved in 1L synthetic very hard water. The $\mathrm{pH}$ and hardness of each type of synthetic water are listed in Table 1.

\section{Preparation of sweetened beverage}

All samples were prepared daily to prevent degradation or precipitation of compounds. Clean glassware was rinsed thoroughly beforehand to remove any residual minerals. Ironcontaining sweetened beverages were obtained by adding five sweeteners respectively into each iron-containing solution in Table 1 to form ace-K beverage $\left(2.64 \times 10^{-4} \mathrm{~g} / \mathrm{mL}\right)$, honey beverage $(0.0624 \mathrm{~g} / \mathrm{mL})$, saccharin beverage $(0.0037 \mathrm{~g} / \mathrm{mL})$, sucralose beverage $\left(9.5 \times 10^{-5} \mathrm{~g} / \mathrm{mL}\right)$ and sucrose beverage $(0.05 \mathrm{~g} / \mathrm{mL})$. The concentrations of above five sweeteners were established based on our previous study (Leitch et al., 2015), which identified sweet equivalence of different sweeteners to a $5 \%$ sucrose in water solution (w/w). 


\subsection{Participant recruitment \& pre-screening test}

This study was approved by the Virginia Tech Institutional Review Board (IRB \#15-399) prior to beginning the sensory test. Participants were faculty, staff and students from Virginia Tech, who were 18 years or older, and did not have a taste disorder that would contribute additional variables to the experimental design. Initially, a pre-test was performed on all participants by simultaneously serving three samples, in a triangle test format, including one ferrous sulfate solution ( $0.3 \mathrm{mg} \mathrm{Fe} / \mathrm{L})$ and two distilled water (in random order). All participants were required not to consume any food or beverage (except water) at least one hour prior to saliva collection. Participants were asked to taste the sample from left to right and select the one considered as metallic flavor. Twenty-five individuals (20 females, age range 20-59) correctly identified ferrous sulfate solution and were recruited as panelists for the following sensory tests.

\subsection{Testing conditions}

Testing was completed in individual booths in the sensory evaluation laboratory. All experimental testing was completed under red lighting to mask any yellow color variation induced by increasing concentrations of ferrous ions in the solutions. Samples were served at room temperature. Participants consumed regular drinking water and unsalted soda crackers to cleanse palate between samples.

\subsection{Pairwise ranking test on synthetic water}

To detect the effect of mineral concentrations on metallic flavor in drinking water, a pairwise ranking test was used to evaluate the metallic taste of each synthetic water (Meilgaard, Civille, \& Carr, 2007). A complete block design was employed on the four types of synthetic water

including soft water (S), moderate hard water (HM), hard water $(\mathrm{HH})$ and very hard water $(\mathrm{VH})$. The 6 comparisons were: S x HM; S x HH; S x VH; HM x HH; HM x VH; HH x VH. Panelists 
were given one comparison at a time and asked to select the sample that tasted more metallic within the pair. If there was no difference between two samples, they had to answer their best guess. Panelists took a large portion of the sample into mouth, swirled it around and expectorated into a cup. To minimize fatigue, participants could eat crackers to clear their palate at any time. The six pairs of samples were presented randomly to 25 panelists and a different random threedigit number was assigned to each sample. The 25 panelists also completed pairwise ranking test on iron-containing sweetened beverages in the following five testing days.

\subsection{Pairwise ranking test on iron-containing sweetened beverage}

Experiment 1. Determining the influence of water chemistry on perception of sweetness of different sweeteners

A pairwise ranking test was used to evaluate the effect of minerals in water on sweetness of different sweeteners (Meilgaard et al., 2007). Each of the five sweeteners was chosen to combine with all 4 synthetic waters [soft water $(\mathrm{S})$, moderate hard water $(\mathrm{HM})$, hard water $(\mathrm{HH})$ and very hard water (VH)] on each testing day. A complete block design was employed for each tested sweetener: S x HM; S x HH; S x VH; HM x HH; HM x VH; HH x VH. The 6 pairs were presented randomly to 25 panelists and each sample was assigned with a different random threedigit number. Panelists were given one comparison at a time and asked to select the sample that was sweeter within the pair. If there was no difference between two samples, they had to answer their best guess.

Experiment 2. Determining if sweeteners reduce the perception of metallic flavor of ironcontaining sweetened beverage

A pairwise ranking test was used to assess the metallic flavor of synthetic waters sweetened by different sweeteners (Meilgaard et al., 2007). Each of the four synthetic waters (soft water, 
moderate hard water, hard water and very hard water) was chosen to combine with all 5

sweeteners on each testing day. Sucrose was used as control to compare with each of the other 4 sweeteners in each type of water: sucrose $\times$ sucralose, sucrose $\times$ saccharin, sucrose $\times$ ace-K, sucrose $\times$ honey. The 4 pairs of sample were presented randomly to 25 panelists and each sample was assigned with a different random three-digit number. Panelists were given one comparison at a time and asked to select the sample that had higher metallic taste. If there was no difference between two samples, they had to answer their best guess. The sensory evaluation started with soft water combinations in order to determine whether sweeteners themselves produced metallic flavor. In each testing day, two pairwise ranking tests were tested by each participant: one test from Experiment 1 (6 pairs of samples) and another test from Experiment 2 (4 pairs of samples). At least half an hour was scheduled between the two tests for all participants each day.

\subsection{Acceptance \& emotional response on iron-containing sweetened beverage}

Panelists were presented with one water sample at a time (six water samples in total). The six water samples with random three-digit number were: soft water, $5 \%$ sucrose in soft water (w/w), hard water with iron $(3 \mathrm{mg} \mathrm{Fe} / \mathrm{L}), 5 \%$ sucrose in hard water with iron (w/w), hard water without iron, $5 \%$ sucrose in hard water without iron $(\mathrm{w} / \mathrm{w})$. Immediately following consumption, panelists rated their acceptability score and selected all applicable emotional terms from the list of 43 terms provided. The list of emotional terms was modified from EsSense ${ }^{\mathrm{TM}}$ paper ballot (King \& Meiselman, 2010), in which 38 of the original 39 terms were used (delete glad) and 5 new terms added including angry, content, fearful, sad, and safe (Leitch et al., 2015).

\subsection{Data analysis}

Data from pairwise ranking test on synthetic waters and iron-containing sweetened beverage-experiment 1 was analyzed by Friedman's T statistic according to Meilgaard et al. 
(2007). Tukey's test $(\alpha=0.05)$ was used to calculate the minimum significant difference.

Experiment 2 was assessed by counting the number of agreeing responses citing one sample more frequently within a pair, and then compared with the critical number of correct response in a two-sided directional difference test $(n=25, \alpha=0.05)$ (Meilgaard et al., 2007).

Hedonic scores of water samples were assessed using one-way ANOVA followed by Tukey's test ( $\alpha=0.05$ ) for mean separation. Emotional terms were analyzed by counting their selection frequency for each water sample. Terms selected for more than $20 \%$ frequency for at least one water sample within group were classified as "frequently selected" terms (Leitch et al., 2015). Among frequently selected terms, terms with less than $8 \%$ difference between tested water samples within group were considered as "shared" terms; terms exhibiting significant difference $(\alpha=0.05)$ between tested water samples and with greater than $12 \%$ selection frequency than other samples within group were classified as “unique” terms. Cochran's Q test was used to assess the minimum significant difference $(\alpha=0.05)$ for each emotional term between tested water samples. Statistical analysis was performed using JMP (JMP vs 10, Cary, NC) and SPSS (Windows, vs 20.0, SPSS inc., Chicago, IL).

\section{Results}

\subsection{Metallic flavor of synthetic waters}

Metallic flavor of the four synthetic waters was detected to establish if the hardness influenced perception. Metallic perception of four types of synthetic waters did not show any significant differences $(\mathrm{p}>0.05)$ from each other. However, HSD value of very hard water (3 mg $\mathrm{Fe} / \mathrm{L})$ was 17.0 when comparing with soft water, which was between alpha of $0.05(\mathrm{HSD}=18.15)$ and $0.1(\mathrm{HSD}=16.2)$. This suggested that metallic flavor of very hard water was detectable by certain number of panelists. Although all the selected panelists had successfully identified 
metallic flavor caused by $\mathrm{FeSO}_{4}(0.03 \mathrm{mg} \mathrm{Fe} / \mathrm{L})$ in distilled water in pre-test, the sensitivity of ferrous sulfate could be reduced due to the existence of other minerals in water as reported by Hoehl et al. (2010).

In the current work, iron (II) sulfate was used to generate metallic sensation in synthetic water and we initially evaluated metallic flavor perception in the synthetic waters. There was no significant differences in metallic perception of synthetic waters with different levels of hardness ( $>0.05$ ) among all pairs, thus we were able to use the four synthetic waters for our study on the taste interactions with sweeteners.

\subsection{Effects of water chemistry on perception of sweetness of sweetened synthetic waters (experiment 1)}

Our hypothesis was that if no interaction occurred between sweeteners and minerals, the perception of sweetness would not be different among the four water conditions. However, sweetness perception was affected by mineral composition/water hardness and varied for the different sweeteners. As shown in Table 2, sweetness of sucralose in hard and very hard water was significantly lower $(\mathrm{p}<0.05)$ than in soft water. Sweetness of sucrose in hard water was significantly lower $(\mathrm{p}<0.05)$ than soft and moderate hard water. Surprisingly, sucrose in very hard water tasted as sweet as in soft and moderate hard water, and was significantly sweeter $(\mathrm{p}<0.05)$ than in hard water. For both ace-K and honey, their combination with hard water generated significantly sweeter taste $(p<0.05)$ than with soft water. Sweetness of honey in moderate hard water was significantly $(\mathrm{p}<0.05)$ lower than in soft and hard water. Mineral content did not significantly ( $p>0.05)$ affect the sweetness of saccharin in all four synthetic waters. 


\subsection{Effect of mineral ions on metallic flavor of sweetened synthetic water (experiment 2)}

To investigate the effect of commercial sweeteners on the metallic flavor of synthetic waters, five sweeteners (sucrose, honey, ace-K, saccharin, and sucralose) were dissolved in one of the synthetic waters on each testing day. The intensity of metallic flavor of water sweetened by each sweetener (except sucrose) was compared with sucrose as a pair. In soft water, ace-K sweetened water had significantly higher $(\alpha=0.05)$ metallic flavor than sucrose (Table 3 ). Moderate hard and hard water further strengthened this metallic taste perception, in which ace-K presented even more obvious $(\mathrm{p}<0.01)$ metallic flavor than sucrose did. However, very hard water reduced the perceptible difference of metallic taste between sucrose and ace-K sweetened water. Similarly, saccharin-sweetened water also showed significantly higher metallic flavor $(p<0.01)$ than sucrose in soft and moderate hard water, while hard and very hard water decreased this taste difference. There was no significant difference in metallic taste between honey and sucrose sweetened water in soft, moderate hard and hard water. Nevertheless, high concentration of minerals in very hard water reacted with honey to generate significantly higher $(\mathrm{p}<0.05)$ metallic flavor. Comparing with sucrose, sucralose-sweetened water did not show any significant difference of metallic flavor in all types of synthetic waters.

\subsection{Results of acceptance test and emotional response}

Acceptance and emotional response of taste perception between low and high water hardness, between low and high ferrous concentration, and with and without sucrose addition were evaluated in this study. As shown in Table 4, very hard water without iron (high water hardness) did not show any significant differences $(\mathrm{p}>0.05)$ in hedonic score compared with soft water (low water hardness). After the addition of $\mathrm{Fe}^{2+}(3 \mathrm{mg} \mathrm{Fe} / \mathrm{L})$, however, the hedonic score of very hard water was significantly reduced $(\mathrm{p}<0.05)$. The decreased acceptability might 
be due to the generation of metallic flavor, since iron (II) sulfate could best be matched to metallic sensation in deionized water (Hoehl et al., 2010). In addition, results in 3.1 also suggested that certain number of panelists had detected the metallic flavor in very hard water.

After adding sucrose in synthetic waters, acceptance of sweetened very hard water $(0 \mathrm{mg}$ $\mathrm{Fe} / \mathrm{L}$ ) was significantly reduced $(\mathrm{p}<0.05)$ compared with sweetened soft water. However, hedonic score of sweetened very hard water $(3 \mathrm{mg} \mathrm{Fe} / \mathrm{L})$ did not show any significance $(\mathrm{p}>0.05)$ with sweetened soft water. A variation of taste acceptance among panelists was observed in this section, since median hedonic score of sweetened soft water was close to sweetened very hard water ( $0 \mathrm{mg} \mathrm{Fe} / \mathrm{L})$ but was higher than sweetened very hard water (3 mg Fe/L).

To further understand consumers' response to taste interactions between sucrose and minerals, emotional profiles generated from sweetened/unsweetened synthetic waters were evaluated by selecting all applicable emotional terms using a modified EsSense ${ }^{\mathrm{TM}}$ paper ballot (King \& Meiselman, 2010; Leitch et al., 2015). Seventeen emotional terms were classified as frequently selected terms ( $\geqslant 20 \%$ selection frequency) for unsweetened synthetic waters and 15 terms were classified as frequently selected terms for sweetened synthetic waters.

Among unsweetened synthetic waters, five frequently selected emotional terms were identified as shared terms, including content, energetic, friendly, good and steady. Cochran's Q test further demonstrated that these five terms did not present any significant difference $(p>0.05)$ between unsweetened synthetic waters (Appendix). Although acceptability between soft water and very hard water $(0 \mathrm{mg} \mathrm{Fe} / \mathrm{L})$ did not show any significant difference, emotional profiles of these two waters were obviously different. As shown in Fig 1(a), emotion distribution of very hard water $(0 \mathrm{mg} \mathrm{Fe} / \mathrm{L})$ was more toward to positive terms, and good-natured, happy, pleasant and satisfied were identified as its unique terms. While emotional terms selected for soft water 
were more neutral words, such like calm and content. Bored and disgusted were unique terms for very hard water ( $3 \mathrm{mg} \mathrm{Fe} / \mathrm{L})$. The unique terms of very hard water $(3 \mathrm{mg} \mathrm{Fe} / \mathrm{L})$ not only explained its low acceptability for consumers, but also demonstrated the emotional response of panelists to the taste perception of ferrous ions.

For sucrose-sweetened synthetic waters, peaceful, pleasant and good-natured were identified as shared terms, as expected. Emotional responses of sweetened soft water were mostly positive terms, in which eager, happy, and satisfied were identified as unique terms (Fig.1). Although sweetened very hard water (3 mg Fe/L) had similar intensity of sweetness and hedonic score with sweetened soft water, distribution of emotional responses were different between these two waters. Emotional profiles of sweetened very hard water ( $3 \mathrm{mg} \mathrm{Fe} / \mathrm{L}$ ) were more toward neutral, low energy terms, such as calm, content, quiet and mild. Mild was determined as unique term for sweetened very hard water (3 $\mathrm{mg} \mathrm{Fe} / \mathrm{L})$. Sweetened very hard water (0 $\mathrm{mg} \mathrm{Fe} / \mathrm{L})$ showed similar distribution of emotional terms with sweetened very hard water (3 mg Fe/L) but with less frequency, especially for energetic and mild. Thus, energetic and mild was speculated as the characteristic emotional profiles of sweet-metallic taste interaction between sucrose and iron.

\section{Discussion}

\subsection{Taste interactions between iron and other minerals in water}

Water hardness (total concentration of $\mathrm{Ca}^{2+}$ and $\mathrm{Mg}^{2+}$ expressed as equivalent $\mathrm{CaCO}_{3}$ ) between 25 and $100 \mathrm{mg} / \mathrm{L}$ were difficult to discriminate for panelists (Byrne, Snyder-Beattie, \& Dietrich, 2009). In addition, water hardness as high as $200 \mathrm{mg} / \mathrm{L}$ was not significantly (p>0.05) different from moderate hard water (50-100 mg/L) in taste (Byrne et al., 2009). Therefore, water hardness in this study did not obviously influence the taste of synthetic waters. We hypothesized 
that higher ferrous sulfate concentration in water would cause higher intensity of metallic sensation. However, in this work, there was no significant differences $(p>0.05)$ in metallic perception between synthetic waters with different levels of ferrous sulfate. One explanation of this result was the existence of other minerals in water samples. Hoehl et al. (2010) reported that metallic perception was affected most by mineral content in water. Recognition thresholds of iron (II) sulfate in tap water $(11.22 \mu \mathrm{mol} / \mathrm{L})$ were significantly higher than in deionized water (5.37 $\mu \mathrm{mol} / \mathrm{L})$ (Hoehl et al., 2010).

Taste threshold concentration (TTC) for sodium in water is 30-60 mg/L (USEPA, 2003) and for magnesium is above $10 \mathrm{mg} / \mathrm{L}$ (Zoeteman, 1978). In this study, concentration of $\mathrm{Na}^{+} \mathrm{and} \mathrm{Mg}^{2+}$ in very hard water has reached their taste threshold and may contribute salty and bitter/metallic flavor to the water. When these two taste stimuli $\left(\mathrm{Na}^{+}\right.$and $\left.\mathrm{Mg}^{2+}\right)$ were mixed with $\mathrm{Fe}^{2+}$ (above threshold), the intensity of this mixture was less than the sum of the individual taste intensities, which is widely known as mixture suppression (Pangborn, 1960; Kroeze, 1982b, 1990; Frank, van der Klaauw, \& Schifferstein, 1993). This may explain the decreased sensitivity of metallic flavor generated by ferrous sulfate in this study. In addition, although other minerals $\left(\mathrm{Ca}^{2+}, \mathrm{K}^{+}\right.$, $\left.\mathrm{Cl}^{-}\right)$in very hard water were all below the taste threshold, they may influence the taste perception of water through subthreshold synergy. Mineral compounds that potentially contribute tastes to water can have an effect as a complex mixture in a perceptible way. For example, different brands of mineral waters were distinguishable in taste, even though their mineral contents were only different in the parts per billion ranges. This was due to the subthreshold minerals and salts combining additively to generate distinguishable tastes (Stevens, 1995). 


\subsection{Taste interactions between sweeteners and minerals in water}

In this study, higher concentration of minerals (moderate-hard) significantly decreased $(p<0.05)$ the sweetness of some sweeteners in water, including sucrose, honey and sucralose. Our results are consistent with the data described by Hoehl et al. (2010), in which higher mineral content in water increased the recognition thresholds of sucrose; sucrose threshold was detected as $3.55 \mathrm{mmol} / \mathrm{L}$ in spring water (lower mineral content) but $5.13 \mathrm{mmol} / \mathrm{L}$ in tap water (higher mineral content). The reduction of sweetness in iron-containing water may be explained by mixture suppression, since both $\mathrm{Fe}^{2+}$ and sweeteners in moderate-hard water has exceeded their threshold and may induce a central cognitive effect through interaction with taste transduction mechanisms (Kroeze \& Bartoshuk, 1985). Another explanation is physio-chemical interactions, which affect taste intensity by changing composition or chemical structure of food compounds. Weak attractive forces (e.g. hydrogen, hydrophobic bonding) between different taste compounds may lead to structure alteration and/or precipitation, which results in a weaker taste or even tasteless perception of these compounds (Keast \& Breslin, 2002a). Although no precipitation was observed in this study, minerals might interact with sweeteners through intermolecular forces and decrease their sweetness. In addition, minerals such as copper may react with saliva proteins to form precipitate in the mouth (Hong, Duncan, Dietrich, O'Keefe, Eigel, \& Mallikarjunan, 2009), which served as a physical barrier between sweetener and taste buds/receptor.

However, for sucrose, ace-K and honey, higher minerals content (hard-very hard) significantly increased $(\mathrm{p}<0.05)$ their sweetness perception in synthetic waters. Mechanisms for sweetness enhancement in mineral water were not consistent. One explanation for this phenomenon was the existence of subthreshold or synergistic side tastes that many compounds elicit. Synergistic side tastes of minerals were spurious in enhancement of taste quality at 
moderate or high concentration in mixtures (Kroeze, 1982a). For example, the sweet taste of dilute $\mathrm{NaCl}$ could significantly increase the sweetness of $\mathrm{NaCl}$-sucrose mixture (Breslin, 1996), when both the concentrations of sucrose and $\mathrm{NaCl}$ were lower than $0.5 \mathrm{M}$ (Graaf \& Frijters, 1989). In the current work, the existence of $\mathrm{Na}^{+}(0.0019 \mathrm{M})$ and $\mathrm{Cl}^{-}(0.00039 \mathrm{M})$ in very hard water might contribute to the significant increase $(p<0.05)$ of the sweetness of sucrose $(0.00015$ M). Sodium chloride may strengthen the sweet perception by interacting with the same receptor of sweeteners in mouth, which is known as peripheral interactions (Keast \& Breslin, 2002a). The very hard water had more bicarbonate, which was described as "sweet" (Matia, 1995) when in high concentration in water. The bicarbonate might also contribute to sweetness independent of sweeteners (Matia, 1995).

Another explanation for the enhancement of sweetness in mineral water was sweet-metallic taste interaction. Metallic taste is a combination of multiple sensations, thus sweet-metallic taste interaction was a comprehensive result of sweet-bitter, sweet-astringent, and sweet-salt interactions. Sweet-bitter interaction originated from the closely related chemical structure and transduction mechanisms between sweet and bitter compounds. Numerous sweeteners and bitter compounds share the same structures including peptides, oximes, urea, terpenes, guanidines and saccharin derivatives (Walters, 1996). This mechanism also explains compounds that tasted both sweet and bitter such as saccharin and ace-K. In addition, a variety of sweet and bitter taste receptors might originate from a common ancestral chemoreceptor (Walters \& Roy, 1996), and they were all mediated by G-protein-coupled receptors (GPCRs) (Walters \& Roy, 1996). For example, when saccharin and ace-K are at low concentrations in water, they express sweet perception by activating sweet tastant-sensing GPCRs-T1R2/T1R3 (Li, Staszewski, Xu, Durick, Zoller, \& Adler, 2002). However, at higher concentration, saccharin and ace-K would activate 
bitter tastant-sensing GPCRs-T2R43 and T2R44, which resulted in bitter/metallic aftertaste of sweeten water (Kuhn, Bufe, Winnig, Hofmann, Frank, Behrens, Lewtschenko, Slack, Ward, \& Meyerhof, 2004). Activated G-protein stimulates an increase of electrical potential in the cell, which eventually results in the enhancement of taste (sweet or bitter) intensity through the nerve system (Walters, 1996). Thus, the mixture of sweeteners and ferrous sulfate in this study might activate more G-proteins receptors than any single stimuli, which leads to the enhancement of taste intensity (Schiffman, 1995; Walters, 1996). However, it is unclear if this effect boosts both bitter and sweetness or only one of these tastes. More study is needed to clarify whether this synergistic effect depends on the ratio and types of sweeteners/bitter compounds.

In our previous work (Leitch et al., 2015), the five sweeteners (concentrations used in this study) generated the same sweetness in the same type of drinking water. However, in this study, sweeteners lead to different levels of metallic flavor in the same type of mineral water.

Ace-K and saccharin-sweetened water were evaluated as higher metallic intensity than sucrose in soft and moderately hard water. Both ace-K and saccharin share the same structure with bitter compounds and can produce metallic/bitter taste themselves at higher concentration (threshold varied) (Rader, Tihanyi, \& Zienty, 1967; Larson-Powers, \& Pangborn, 1978; Ott, Edwards, \& Palmer, 1991). The generation of metallic aftertaste is through activation of bitterness receptors including TAS2R family (hTAS2R43 and hTAS2R44) and TVR1. TAS2R family was able to stimulate bitter/metallic taste while blocking the expression of sweet taste in cells (Kuhn et al., 2004). TRPV1 was correlated with the metallic aftertaste of saccharin and aceK (Riera, Vogel, Simon, \& Coutre, 2007). Higher concentration of $\mathrm{Cu}^{2+}, \mathrm{Zn}^{2+}$ and $\mathrm{Fe}^{2+}$ were also found to be able to activate TRPV1 (Riera et al., 2007), which might further strengthen the metallic flavor of saccharin/ace-K sweetened mineral water. 
However, in hard/very hard water, the difference between sucrose and ace-K/saccharin in metallic intensity was obviously decreased. This result might be explained by the high metallic taste of ferrous ions in hard $(1 \mathrm{mg} \mathrm{Fe} / \mathrm{L})$ and very hard $(3 \mathrm{mg} \mathrm{Fe} / \mathrm{L})$ water, which covered the metallic aftertaste of ace-K and saccharin. Furthermore, it suggested that the metallic aftertaste of ace-K might be stronger than saccharin, since under the same condition (hard water), the significant metallic flavor $(\mathrm{p}<0.05)$ of ace-K was still present while in saccharin it was not. AceK was reported to have a delayed bitter aftertaste (Ott et al., 1991), which might strengthen the intensity of its metallic flavor and extend its duration.

Honey-sweetened water exhibited significantly higher $(\mathrm{p}<0.05)$ metallic flavor than sucrose in very hard water. Generally, main taste compounds in honey were from sugars, such as fructose and glucose. The quantity and types of acids and amino acids present in honey may also influence its aroma and flavor (Bogdanov, Jurendic, Sieber, \& Gallmann, 2008). Polyphenols, which are traditionally considered as antioxidant components in honey, are reported to cause bitterness and astringency in foods such as tea, red wine and several types of fruits (Lesschaeve \& Noble, 2005). Therefore, polyphenols might contribute a side taste to honey and potentially change the sensory characteristics of honey in certain conditions. In addition, honey contains a variety of minerals ( $\mathrm{Fe}, \mathrm{Mn}, \mathrm{Pb}, \mathrm{Cd}, \mathrm{Zn}, \mathrm{Cu}, \mathrm{Cr}, \mathrm{Ni})$, which are derived from natural resources and air or soil contamination of anthropogenic sources. It has been reported that metal ions constitute a large proportion of minerals found in honey, especially Fe ranging 0.136-9.852 $\mathrm{mg} / \mathrm{kg}$ (mean $1.390 \mathrm{mg} / \mathrm{kg}$ ), Cu ranging 0.051-3.317 mg/kg (mean $0.656 \mathrm{mg} / \mathrm{kg}$ ), Zn ranging 0.016-4.133 mg/kg (mean $1.041 \mathrm{mg} / \mathrm{kg}$ ), and Mn ranging 0.125-12.354 mg/kg (mean 2.063 mg/kg) (Bogdanov, Haldimann, Luginbühl, \& Gallmann, 2007). The abundance of metal ions in 
honey might increase the mineral levels of honey-sweetened water samples in this study, which might explain the significant enhancement of metallic taste of honey in very hard water.

Sucralose is produced by selectively substituting three of the hydroxyl groups of sucrose with chlorine atoms (Fraser-Reid, 2012). The pleasant sweet perception of sucralose is very close

to sucrose (Arora, Singh, Sharma, Wadhwa, George, Singh, \& Sharma, 2009), and there is no bitter or metallic aftertaste for sucralose. However, sucralose is reported to be $450-650$ times sweeter than sucrose (Arora et al., 2009) and does not provide any calories. Potentially the human brain response can distinguish the caloric sweetener (sucrose) from the non-caloric sweetener (sucralose), and the body does not metabolically process sucralose. Even though sucrose and sucralose share the same primary taste pathway, they activate different areas in brain and with different intensity of response (Frank, Obernadorfer, Simmons, Paulus, Fudge, Yang, \& Kaye, 2008). Therefore, sucrose may interact with mineral ions to alter taste perception through the stimulation of its unique neural signal transduction mechanism (cognitive interactions) (Keast \& Breslin, 2002a). This explains the significant enhancement of sweetness in sucrosesweetened synthetic waters rather than sucralose-sweetened synthetic waters in this study.

\subsection{Acceptance and emotional response of taste interactions}

Consumer's rating of liking on a taste mainly depends on its bitterness rather than sweetness (Kamerud \& Delwiche, 2007). That is, consumers who rated a food high in sweetness were not always more likely to rate it high for liking. Correspondingly, if a food was tasted more than "moderate" in bitterness, its liking rated by consumers was neutral or lower (Kamerud \& Delwiche, 2007). Both bitterness and astringency were reduced by sucrose in beverages (Keast, 2008; Ishikawa \& Noble, 1995). Therefore, the addition of sucrose in very hard water (3mg $\mathrm{Fe} / \mathrm{L}$ ) in this study might largely reduce the metallic/bitter taste of ferrous ions, which 
significantly increased its liking rate. Emotional response of panelists may further prove this statement, since bored and disgusted were unique terms for very hard water ( $3 \mathrm{mg} \mathrm{Fe} / \mathrm{L})$ while mild was unique term for sweetened very hard water (3mg Fe/L).

In contrast, addition of sucrose significantly decreased $(\mathrm{p}<0.05)$ the liking rating of very hard water $(0 \mathrm{mg} \mathrm{Fe} / \mathrm{L})$ and reduced the selection frequency of emotional terms including goodnatured, happy, pleasant and satisfied. The production of delightful taste of very hard water (0mg Fe/L) might be due to its appropriate concentration of total dissolved solids (TDS). Platikanov et al. (2013) found that the most important factor that influenced water taste and preference was the overall level of mineralization (TDS). Panelists disliked very high mineralized water (TDS $>800 \mathrm{mg} / \mathrm{L}$ ) and very low mineralized water (TDS $<30-40 \mathrm{mg} / \mathrm{L}$ ) (Platikanov, Garcia, Fonseca, Rullan, Devesa, \& Tauler, 2013). In the current study, TDS in soft water might be too low to generate pleasant taste perception. Furthermore, in a study about taste preference of tap and commercial bottled waters, soft water was found to have a plastic taste according to sensory tests and could not be differentiated from distilled water (Dietrich \& Burlingame, 2015). On the other hand, Lawless, Rapacki, Horne, Hayes, \& Wang (2004) found that even though sucrose could partially mask the bitterness of calcium chloride, calcium salts were also observed to suppress the sweetness of sucrose. Since minerals may interact with salivary proteins to form precipitates in the mouth, water hardness might reduce the sweetness of sucrose through the formation of physical barrier between sucrose and sweet receptors in taste buds.

\section{Conclusion}

Effect of water chemistry on taste perception of sweetened synthetic waters was varied with different concentrations of minerals and with different types of sweeteners. In the beverage 
industry, sucrose, ace-K and honey may be considered as sweeteners for products containing high level of minerals. Since minerals $\left(\mathrm{Fe}^{2+}, \mathrm{Na}^{+}, \mathrm{Ca}^{2+}, \mathrm{Mg}^{2+}, \mathrm{K}^{+}, \mathrm{Cl}^{-}\right)$at certain concentration (moderate-hard water) can amplify the sweet perception through taste interaction, the observations in this study may be applied to reduce the use (cost) of sweeteners in production. According to the relatively high acceptability and positive emotional response, sucrose may serve as the sweetener in beverage products containing bitter/metallic metal ions. Although not proven in acceptance test, ace-K, saccharin, and sucralose may be suitable calorie-free sweeteners for beverage with bitter/metallic metal ions. High level of metal ions may cover the metallic aftertaste of ace- $\mathrm{K}$ and saccharin, but without decreasing their sweetness perception. The high sweet intensity of ace-K (200 times sweeter than sucrose) and saccharin (300-400 times sweeter than sucrose) make them to be the economical sugar substitute in sweetened beverage. Even though water chemistry will reduce sweetness of sucralose, the taste perception of sucralose is still close to sucrose and without any bitter/metallic aftertaste. Due to its high intensity of sweetness (600 times sweeter than sucrose), low price ( $15 \%$ of sucrose), and relatively high safety, sucralose is still considered as an economic calorie-free sugar substitute in the food industry.

Sweet-metallic taste interaction may extend its application to other food products containing bitter/metallic constituents, such as polyphenol, tannin, glycosides, some amino acids and metal ions. Its potential in amplifying sweetness and increasing acceptability may be able to mask inherent metallic taste of functional food/beverage, supplements or medicine that are fortified by health beneficial components but with poor taste quality. Metallic sensation is a combination of metal taste on the tongue and retronasal odor of carbonyls and other volatile organic compounds. 
Therefore, taste-odor interaction should also be considered in reducing metallic sensation in future studies, especially the application of compounds with fruit aroma such as ethyl butyrate.

\section{Acknowledgements}

This project was funded, in part, by the Virginia Agricultural Experiment Station, the Hatch Program of the National Institute of Food and Agriculture, U.S. Department of Agriculture, and the Virginia Tech Water INTERface Interdisciplinary Graduate Education Program.

\section{References}

Arora, S., Singh, V. P., Sharma, V., Wadhwa, B.K., George, V., Singh, A.K., \& Sharma, G.S. (2009). Analysis of sucralose and its storage stability in burfi. Journal of Food Science and Technology (Mysore), 46(2), 114-117.

Ayya, N., \& Lawless, H.T. (1992). Quantitative and qualitative evaluation of high-intensity sweeteners and sweetener mixtures. Chemical Senses, 17, 245-259.

Bartoshuk, L.M., \& Cleveland, C.T. (1977). Mixtures of substances with similar tastes. A test of a psychophysical model of taste mixture interactions. Sensory Processes, 1(3), 177-186.

Beebe-Center, J. G., Rogers, M. S., Atkinson, W. H., \& O’Connell, D. W. (1959). Sweetness and saltiness of compound solutions of sucrose and $\mathrm{NaCl}$ as a function of concentration of solutes. Journal of Experimental Psychology, 57, 231-234.

Bogdanov, S., Haldimann, M., Luginbühl, W., \& Gallmann, P. (2007). Minerals in honey: environmental, geographical and botanical aspects. Journal of Apicultural Research \& Bee World, 46(4), 269-275.

Bogdanov, S., Jurendic, T., Sieber, R., \& Gallmann, P. (2008). Honey for nutrition and health: a review. Journal of the American College of Nutrition, 27(6), 677-689.

Breslin, P. A., \& Beauchamp, G. K. (1995). Suppression of bitterness by sodium: variation among bitter taste stimuli. Chemical Senses, 20, 609-623. 
Breslin, P. A. S. (1996). Interactions among salty, sour and bitter compounds. Trends in Food Science \& Technology, 7, 390-399.

Breslin, P. A., \& Beauchamp, G. K. (1997). Salt enhances flavour by suppressing bitterness. Nature, 387-463.

Burlingame, G. A., Dietrich, A. M., \& Whelton, A. J. (2007). Understanding the basics of tap water taste. Journal of American Water Works Association, 99, 100-111.

Byrne, T., Snyder-Beattie, A., \& Dietrich, A. (2009). The sensory perception of drinking water hardness. NSF REU Proceedings of Research, 26.

Calvino, A. M., Garcia-Medina, M. R., \& Cometto-Muniz, J. E. (1990). Interactions in caffeinesucrose and coffee-sucrose mixtures: evidence of taste and flavor suppression. Chemical Senses, 15, 505-519.

Cuppett, J.D., Duncan, S.E., \& Dietrich, A.M. (2006). Evaluation of copper speciation and water quality factors that affect aqueous copper tasting response. Chemical Senses, 31, 689697.

Curtis, D. W., Stevens, D. A., \& Lawless, H. T. (1984). Perceived intensity of the taste of sugar mixtures and acid mixtures. Chemical Senses, 9, 107-120.

DES. (2008). Hardness in drinking water. Environmental Fact Sheet. WD-DWGB-3-6.

Dietrich, A. M., Glindemann, D., Pizarro, F., Gidi, V., Olivares, M., Araya, M., Camper, A., Duncan, S., Dwyer, S., Whelton, A., Younos, T., Subramanian, S., Burlingama, G. A., Khiari, D., \& Edwards, M. (2004). Health and aesthetic impacts of copper corrosion on drinking water. Water Science \& Technology, 49(2), 55-62.

Dietrich, A., \& Burlingame, G. (2015). Critical review and rethinking of USEPA secondary standards for maintaining organoleptic quality of drinking water. Environmental Science and Technology, 49, 708-720.

Duranceau, S., Wilder, R., \& Douglas, S. (2012). Guidance and recommendations for posttreatment of desalinated water. Journal of American Water Works Association, 104 (9), E510-520.

Frank, R. A., van der Klaauw, N. J., \& Schifferstein, H. (1993). Both perceptual and conceptual factors influence taste-odor and taste interactions. Perception and Psychophysics, 54, $343-354$. 
Frank, G.K.W., Obernadorfer, T.A., Simmons, A.N., Paulus, M.P., Fudge, J.L., Yang, T.T., \& Kaye, W.H. (2008). Sucrose activates human taste pathways differently from artificial sweetener. NeuroImage, 39, 1559-1569.

Fraser-Reid, B. (2012). From Sugar to Splenda. Springer-Verlag Berlin. DOI 10/1007/978-3642-22781-3_1

Graaf, C.D., \& Frijters, E.R. (1989). Interrelationships among sweetness, saltiness and total taste intensity of sucrose, $\mathrm{NaCl}$ and sucrose/ $\mathrm{NaCl}$ mixtures. Chemical Senses, 14, 81-102.

Hoehl, K., Schoenberger, G.U., \& Busch-Stockfisch, M. (2010). Water quality and taste sensitivity for basic tastes and metallic sensation. Food Quality and Preference, 21, 243249.

Horne, J., Lawless, H.T., Speirs, W., \& Sposato, D. (2002). Bitter taste of saccharin and acesulfame-k. Chemical Senses, 27, 31-38.

Ishikawa, T., \& Noble, A.C. (1995). Temporal perception of astringency and sweetness in red wine. Food Quality and Preference, 6, 27-33.

Hong, J. H., Duncan, S. E., \& Dietrich, A. M. (2009). Effect of copper speciation at different pH on temporal sensory attributes of copper. Food Quality and Preference, 21(1), 132-139.

Hong, J. H., Duncan, S. E., Dietrich, A. M., O’Keefe, S. F., Eigel, W. N., \& Mallikarjunan, K. (2009). Interaction of copper and human salivary proteins. Journal of Agricultural and Food Chemistry, 57(15), 6967-6975.

Jesse, M., Cohen, L. J., Kamphake, E. K., \& Richard, L. (1960). Taste threshold concentrations of metals in drinking water. Journal of American Water Works Association, 52(5), 660670.

Kamerud, J.K., \& Delwiche, J.F. (2007). Individual differences in perceived bitterness predict liking of sweeteners. Chemical Senses, 32, 803-810.

Keast, R.S.J., \& Breslin, P.A.S. (2002a). An overview of binary taste-taste interactions. Food Quality and Preference, 14, 111-124.

Keast, R. S. J., \& Breslin, P. A. S. (2002b). Modifying the bitterness of selected oral pharmaceuticals with cation and anion series of salts. Pharmacy Research, 19(7), 10191026.

Keast, R. S. J. (2008). Modification of the bitterness of caffeine. Food quality and preference, 19(5), 465-472. 
King, S. C., \& Meiselman H L (2010). Development of a method to measure consumer emotions associated with foods. Food Quality and Preference, 21(2), 168-177.

Kroeze, J.H.A. (1982a). The relationship between the side tastes of masking stimuli and masking binary mixtures. Chemical Senses, 7, 23-37.

Kroeze, J. H. (1982b). The influence of relative frequencies of pure and mixed stimuli on mixture suppression in taste. Perception and Psychophysics, 31, 276-278.

Kroeze, J. H., \& Bartoshuk, L. M. (1985). Bitterness suppression as revealed by split-tongue taste stimulation in humans. Physiology and Behavior, 35, 779-783.

Kuhn, C., Bufe, B., Winnig, M., Hofmann, T., Frank, O., Behrens, M., Lewtschenko, T., Slack, J.P., Ward, C.D., \& Meyerhof, W. (2004). Bitter taste receptors for saccharin and acesulfame K. The Journal of Neuroscience, 24(45), 10260-10265.

Larson-Powers, N., \& Pangborn, R.M. (1978). Paired comparison and time-intensity measurements of the sensory properties of beverages and gelatins containing sucrose or synthetic sweeteners. Journal of Food Science, 43, 47-51.

Lauer, W. C. (2004). Water Quality Complaint Investigator's Field Guide; American Water Works Association: Denver, CO, Vol. 105, p 105.

Lawless, H.T., Rapacki, F., Horne, J., Hayes, A., \& Wang, G. (2004). The taste of calcium chloride in mixtures with $\mathrm{NaCl}$, sucrose and citric acid. Food Quality and Preference, 15, 83-89.

Leitch, K.A., Duncan, S.E., O’Keefe, S., Rudd, R., \& Gallagher, D.L. (2015). Characterizing consumer emotional response to sweeteners using an emotion terminology questionnaire and facial expression analysis. Food Research International, 76, 283-292.

Lesschaeve, I., \& Noble, A. (2005). Polyphenols: factors influencing their sensory properties and their effects on food and beverage preferences. The American Journal of Clinical Nutrition, 81, 3305-3355.

Li, X., Staszewski, L., Xu, H., Durick, K., Zoller, M., \& Adler, E. (2002). Human receptors for sweet and umami taste. Proceedings of the National Academy of Sciences USA, 99, 4692-4696.

Matia, L. (1995). Treatment of tastes in drinking water: Causes and control. In: Advances in Taste-and-Odour Treatment and Control, Edited by I.H. Suffet, J. Mallevialle, E. 
Kawczynski. American Water Works Association Research Foundation and Lyonnaise des Eaux, Denver, CO.

Meilgaard, M., Civille, G., \& Carr, B. T. (2007). Sensory Evaluation Techniques, 4th ed.; CRC Press: Boca Raton, FL.

Mirlohi, S., Dietrich, A.M., \& Duncan, S.E. (2011). Age-associated variation in sensory perception of iron in drinking water and the potential for overexposure in the human population. Environmental Science and Technology, 45, 6575-6583.

Ömur-Özbek, P., \& Dietrich, A. (2011). Retronasal perception and flavor thresholds of iron and copper in drinking water. Journal of Water Health, 9, 1-9.

Ott, D.B., Edwards, C.L., \& Palmer, S.J. (1991). Perceived taste intensity and duration of nutritive and non-nutritive sweeteners using time-intensity evaluations. Journal of Food Science, 56, 535-542.

Pangborn, R.M. (1960). Taste interrelationships. Food Research, 25, 245-256.

Platikanov, S., Garcia, V., Fonseca, I., Rullán, E., Devesa, R., \& Tauler, R. (2013). Influence of minerals on the taste of bottled and tap water: a chemometric approach. Water Research, 47, 693-704.

Rader, C.P., Tihanyi, S.G., \& Zienty, F.B. (1967). A study of the true taste of saccharin. Journal of Food Science, 32, 357-360.

Riera, C.E., Vogel, H., Simon, S.A., \& Coutre, J. (2007). Artificial sweeteners and salts producing a metallic taste sensation activate TRPV1 receptors. American Journal of Physiology. Regulatory, Integrative and Comparative Physiology, 293, 626-634.

Sarin, P., Snoeyink, V.L., Lytle, D.A., \& Kriven, W.M. (2004). Iron corrosion scales: model for scale growth, iron release, and colored water formation. Journal of Environmental Engineering, 130, 364-373.

Schiffman, S. S., Gatlin, L. A., Sattely-Miller, E. A., Graham, B. G., Heiman, S. A., Stagner, W. C., \& Erickson, R. P. (1994). The effect of sweeteners on bitter taste in young and elderly subjects. Brain Research Bulletin, 35, 189-204.

Schiffman, S.S. (1995). Investigation of synergism in binary mixtures of sweeteners. Brain Research Bulletin, 38, 105-120.

Smith, E.J., Davison, W., \& Hamilton-Taylor, J. (2002). Methods for preparing synthetic freshwaters. Water Research, 36, 1286-1296. 
Stevens, J.C. (1995). Detection of heteroquality taste mixtures in perception. Psychophysiology, $57,18-26$.

USEPA. (2003). Drinking Water Advisory: Consumer Acceptability Advice and Health Effects Analysis on Sodium EPA 822-R-03-006; US Environmental Protection Agency: Washington, DC, p 29.

USEPA. (2016). National Secondary Drinking Water Standards. January 6. http://www.epa.gov/dwstandardsregulations/secondary-drinking-water-standardsguidance-nuisance-chemicals.

Walsh, A. M., Duncan, S. E., Potts, H., \& Gallagher, D.L (2015). Comparing quality and emotional responses as related to acceptability of light-induced oxidation flavor in milk. Food Research International, 76, 293-300.

Walters, D.E. (1996). How are bitter and sweet tastes related? Trends in Food Science \& Technology, 7, 399-403.

Walters, D.E., \& Roy, G. (1996). Taste interactions of sweet and bitter compounds. Flavor-Food Interactions (McCorrin, R.E. and Leland, J.V., eds). American Chemical Society, Washington, DC, pp 130-142.

Woskow, M. H. (1969). Selectivity in flavor modification by 5'-ribonucleotides. Food Technology, 23, 32-37.

Yamaguchi, S. (1967). The synergistic taste effect of MSG and disodium 5'-inosinate. Journal of Food Science, 32, 473-478.

Zoeteman, B.C.J. (1978). Sensory assessment and chemical composition of drinking water. Published doctoral thesis, Utrecht University, Van de Gang, The Hague. 


\section{List of Figures}

Fig.1 Frequency distribution of emotion terms that frequently selected by panelists $(n=25)$ for: (a) soft water, very hard water $(0 \mathrm{mg} \mathrm{Fe} / \mathrm{L})$ and very hard water $(3 \mathrm{mg} \mathrm{Fe} / \mathrm{L})$; (b) soft water + sucrose, very hard water $(0 \mathrm{mg}$ Fe/L) + sucrose, and very hard water $(3 \mathrm{mg} \mathrm{Fe} / \mathrm{L})+$ sucrose. The displayed emotional terms were more than $20 \%$ of selection frequency for at least one water sample within group. Terms denoted with an asterisk were shared terms which had a difference in frequency $\leq 8 \%$ among three samples in the group. Terms denoted with two asterisks were unique terms which used for one sample having a difference in frequency $\geq 12 \%$ than the other two samples in the group. 
Table 1. Preparation of iron-containing synthetic water using reagent grade chemicals ${ }^{1}$

\begin{tabular}{|c|c|c|c|c|c|c|c|c|}
\hline \multirow[t]{2}{*}{ Water Type } & \multicolumn{5}{|c|}{ Reagent Added $(\mathrm{mg} / \mathrm{L})^{2}$} & \multicolumn{3}{|c|}{ Final Water Quality } \\
\hline & $\mathrm{FeSO}_{4} \cdot 7 \mathrm{H}_{2} \mathrm{O}$ & $\mathrm{NaHCO}_{3}$ & $\mathrm{CaSO}_{4} \cdot 2 \mathrm{H}_{2} \mathrm{O}$ & $\mathrm{MgSO}_{4} \cdot 7 \mathrm{H}_{2} \mathrm{O}$ & $\mathrm{KCl}$ & $\mathrm{pH}^{3}$ & Hardness $^{4}$ & $\begin{array}{c}\text { TDS } \\
(\mathrm{mg} / \mathrm{L})\end{array}$ \\
\hline Soft & 0.0 & 21.2 & 45.6 & 15.4 & 3.8 & 7.2-7.4 & 33 & 68.6 \\
\hline Moderately Hard & 1.5 & 53.0 & 114.0 & 38.5 & 9.6 & 7.4-7.6 & 82 & 172.2 \\
\hline Hard & 5.0 & 105.9 & 227.9 & 77.0 & 19.1 & 7.6-7.8 & 163 & 345.6 \\
\hline Very Hard & 14.9 & 158.9 & 341.9 & 115.5 & 28.7 & $8.0-8.2$ & 245 & 522.4 \\
\hline & $\mathrm{Fe}^{2+}$ & $\mathrm{Na}^{+}$ & $\mathrm{Ca}^{2+}$ & $\mathrm{Mg}^{2+}$ & $\mathrm{K}^{+}$ & & & \\
\hline Soft & 0.0 & 5.8 & 10.6 & 1.5 & 2.0 & & & \\
\hline Moderately Hard & 0.3 & 14.5 & 26.5 & 3.8 & 5.0 & & & \\
\hline Hard & 1.0 & 29.0 & 53.0 & 7.5 & 10.0 & & & \\
\hline Very Hard & 3.0 & 43.5 & 79.5 & 11.3 & 15.0 & & & \\
\hline
\end{tabular}

${ }^{1}$ Source: Burlingame et al., 2007 and Smith et al., 2002.

${ }^{2}$ Food-grade reagents were added to distilled water.

${ }^{3}$ Equilibrium $\mathrm{pH}$ after $24 \mathrm{~h}$ of aeration.

${ }^{4}$ Expressed as $\mathrm{mg} / \mathrm{L} \mathrm{CaCO}_{3}$ (DES, 2008). 
Table 2. Rank sum values of each synthetic water with and without the addition of sweeteners (experiment 1 ) according to pairwise ranking test $(\mathrm{n}=25)$ followed with Turkey's test $(\alpha=0.05)$

\begin{tabular}{lccccc}
\hline & Soft Water $^{1}$ & $\begin{array}{c}\text { Moderate Hard } \\
\text { Water }\end{array}$ & Hard Water & Very Hard Water & HSD Value $^{2}$ \\
\hline No sweetener & $119^{\mathrm{a}}$ & $116^{\mathrm{a}}$ & $113^{\mathrm{a}}$ & $102^{\mathrm{a}}$ & \\
$\begin{array}{l}\text { Sucrose } \\
(0.05 \mathrm{~g} / \mathrm{mL})\end{array}$ & $103^{\mathrm{b}}$ & $98^{\mathrm{b}}$ & $132^{\mathrm{a}}$ & $99^{\mathrm{b}}$ & \\
$\begin{array}{l}\text { Ace-K } \\
\left(2.64 \times 10^{-4} \mathrm{~g} / \mathrm{mL}\right)\end{array}$ & $113^{\mathrm{a}}$ & $106^{\mathrm{ab}}$ & $89^{\mathrm{b}}$ & $106^{\mathrm{ab}}$ & \\
$\begin{array}{l}\text { Honey } \\
(0.0624 \mathrm{~g} / \mathrm{mL})\end{array}$ & $123^{\mathrm{b}}$ & $145^{\mathrm{a}}$ & $90^{\mathrm{c}}$ & $128^{\mathrm{ab}}$ & $(\alpha=0.05)$ \\
$\begin{array}{l}\text { Saccharin } \\
(0.0037 \mathrm{~g} / \mathrm{mL})\end{array}$ & $104^{\mathrm{a}}$ & $117^{\mathrm{a}}$ & $112^{\mathrm{a}}$ & $114^{\mathrm{a}}$ & \\
$\begin{array}{l}\text { Sucralose } \\
\left(9.5 \times 10^{-5} \mathrm{~g} / \mathrm{mL}\right)\end{array}$ & $103^{\mathrm{b}}$ & $109^{\mathrm{ab}}$ & $127^{\mathrm{a}}$ & $126^{\mathrm{a}}$ & \\
\hline
\end{tabular}

${ }^{1}$ Water was synthesized by adding food-grade reagents into distilled water, as described in 2.2. ${ }^{2} \mathrm{HSD}$ value was calculated according to Meilgaard et al. (2007). If the difference in rank sum between any two synthetic waters in the same row were greater than the HSD value, then these two water samples showed significant differences $(p<0.05)$ in taste perception.

${ }^{a-c}$ Means within each row with different superscripts are significantly different $(p<0.05)$. Lower rank sum value means the sample is sweeter. 
Table 3. Number of responses on sweetened synthetic water with higher metallic flavor (experiment 2 ) according to pairwise ranking test $(\mathrm{n}=25)$ and the corresponding critical value $(\alpha=0.05)$

\begin{tabular}{ccccccccc}
\hline & \multicolumn{2}{c}{ Pair 1 $^{\mathbf{1}}$} & \multicolumn{2}{c}{ Pair 2 } & \multicolumn{2}{c}{ Pair 3 } & \multicolumn{2}{c}{ Pair 4 } \\
& Sucrose $^{2}$ & Ace-K & Sucrose & Honey & Sucrose & Saccharin & Sucrose & Sucralose \\
\hline Soft water & 6 & $19^{*}$ & 8 & 17 & 2 & $22^{* *}$ & 9 & 16 \\
Moderate hard water & 4 & $21^{* *}$ & 10 & 15 & 5 & $20^{* *}$ & 9 & 16 \\
Hard water & 4 & $21^{* *}$ & 8 & 17 & 8 & 17 & 8 & 17 \\
Very hard water & 8 & 17 & 7 & $18^{*}$ & 8 & 17 & 11 & 14 \\
Critical number & & & \multicolumn{2}{c}{$18(\alpha=0.05), 20(\alpha=0.01)$} & & & \\
\hline
\end{tabular}

${ }^{1}$ Sucrose was served as control; each sweetener was compared with sucrose in the same type of water.

${ }^{2}$ Concentration of each sweetener: sucrose, $0.05 \mathrm{~g} / \mathrm{mL}$; ace-K, $2.64 \times 10-4 \mathrm{~g} / \mathrm{mL}$; honey, 0.0624 $\mathrm{g} / \mathrm{mL}$; saccharin, $0.0037 \mathrm{~g} / \mathrm{mL}$; sucralose, $9.5 \times 10^{-5} \mathrm{~g} / \mathrm{mL}$. Sweetness was established as equal sweet to sucrose as reported by Leitch et al. (2015).

${ }^{3}$ Water was synthesized by adding food-grade reagents into distilled water, as described in 2.2. ${ }^{4}$ Critical number was found in Table 17.12 (Meilgaard et al. 2007). The critical number is the minimum number of responses required for significance $(\alpha=0.05)$ for 25 respondents. If the number of responses was greater than or equal to the selected critical number, there was significant difference between two samples at the stated $\alpha$-level.

*Means the sample within a pair had significantly higher metallic flavor $(\mathrm{p}<0.05) ;{ }^{* *}$ means the sample within a pair had significantly higher metallic flavor $(\mathrm{p}<0.01)$. 
Table 4. Mean hedonic scores ${ }^{1}(n=25)$ for synthetic waters with and without the addition of iron and sucrose

\begin{tabular}{|c|c|c|c|c|}
\hline Water Sample ${ }^{2}$ & Mean & SD & $95 \% \mathrm{Cl}$ & Median \\
\hline \multicolumn{5}{|c|}{ Taste interaction between water hardness and sucrose } \\
\hline Soft water & $5.7^{\mathrm{ab}}$ & 1.4 & $5.1-6.3$ & 5.5 \\
\hline Soft water + sucrose & $6.0^{\mathrm{a}}$ & 2.2 & $5.1-6.9$ & 7 \\
\hline Very hard water (0mg Fe/L) & $5.9^{\mathrm{a}}$ & 2.0 & $5.1-6.8$ & 5 \\
\hline Very hard water $(0 \mathrm{mg}$ Fe/L $)+$ sucrose & $4.5^{\mathrm{b}}$ & 1.3 & $4.0-5.1$ & 6.5 \\
\hline \multicolumn{5}{|c|}{ Taste interaction between iron, water hardness and sucrose } \\
\hline Soft water & $5.7^{\mathrm{a}}$ & 1.4 & $5.1-6.3$ & 5.5 \\
\hline Soft water + sucrose & $6.0^{\mathrm{a}}$ & 2.2 & $5.1-6.9$ & 7 \\
\hline Very hard water (3mg Fe/L) & $4.1^{\mathrm{b}}$ & 1.6 & $3.4-4.8$ & 5 \\
\hline Very hard water $(3 \mathrm{mg} \mathrm{Fe} / \mathrm{L})+$ sucrose & $5.5^{\mathrm{a}}$ & 1.6 & $4.8-6.3$ & 5.5 \\
\hline
\end{tabular}

${ }^{1}$ Acceptance test was evaluated by 9 -point hedonic score test; $1=$ extremely dislike, $9=$ extremely like. Hedonic scores for all samples were normally distributed.

${ }^{2}$ Water was synthesized by adding food-grade reagents into distilled water, as described in 2.2. ${ }^{a-b}$ Means water samples with different letters in each column were significantly different $(\mathrm{p}<0.05)$ from each other in mean hedonic score. 


\section{Figure 1}

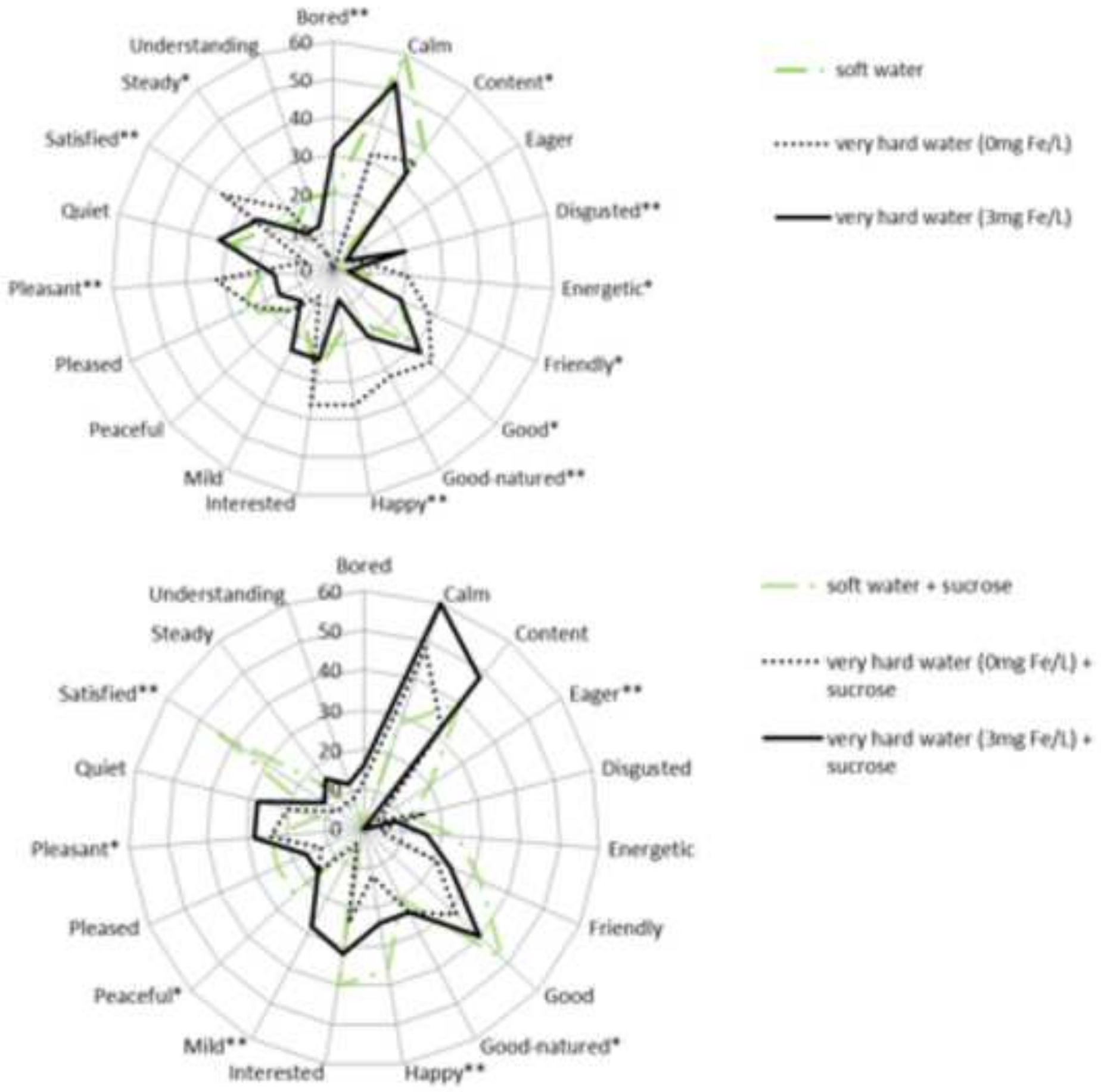

